\title{
Academic Leadership in a Private University: An Iranian Case Study
}

\author{
Fatemeh Hamidifar ${ }^{1} \&$ Mansoureh Ebrahimi ${ }^{2}$ \\ ${ }^{1}$ Faculty of Management, Islamic Azad University, Central Tehran Branch, Tehran, Iran \\ ${ }^{2}$ Faculty of Islamic Civilization, Universiti Teknologi Malaysia, Malaysia, Johor, Malaysia \\ Correspondence: Fatemeh Hamidifar, Islamic Azad University, Central Tehran Branch, No. 128, Azadi Avenue, \\ PO box 13117-73591, Tehran, Iran. E-mail: fatimehh@gmail.com
}

Received: October 20, 2015 Accepted: November 21, 2015 Online Published: April 26, 2016

doi:10.5539/ies.v9n5p193 URL: http://dx.doi.org/10.5539/ies.v9n5p193

\begin{abstract}
This study explores effective academic leadership as well as hindrances within Iran's private higher educational institutions. The author employed a qualitative approach that utilized purposive sampling to collect and analyze data. Findings were categorized into three classes comprising the (i) setting of direction, (ii) organizational and (iii) staff development at three administrative levels: central office, branch office and faculty personnel. Obstacles confronting effective academic leadership were identified as (i) centralization of power; (ii) bureaucratic hierarchy; (iii) budgetary restraints; (iv) ineffective interaction including ineffectual communications as well as social, political and cultural interventions; and (v) unqualified staffing policies that eschewed meritocracy. This study reveals that the functional purview of an effective academic leader is to drive an institution's vision forward towards achievement and define its mission and objectives. Moreover, it signifies an indispensable need for academic leadership development programs that incorporate, protect and support scientific management skills based on sound moral values, mutually established trust, collegial respect, and the application of transactional cum transformational governance methods in teaching, learning and research.
\end{abstract}

Keywords: academic leadership, effectiveness, barriers, private universities, Iran

\section{Introduction}

A rising demand for research on leadership skills in higher education venues presently commands much attention. It has become a necessity to further develop academic human resources at a time of change in which the needs of increasing student numbers must be met. Leaders in academic settings play important roles in the development and support of appropriate alliances with higher educational and social institutions that satisfy societal demands and requirements. Our technological digital era and knowledge-based economies have placed universities in key developmental positions that promote both infrastructural growth and the maintenance of cultural identity. Hence, it has become necessary to develop a formidable academic cadre of leaders who can engage and effectively manage faculty and administrative staff during this time of transition to accommodate social, political, economic and educational complexities (Wisniewski, 2007). Human resource policies towards academic management, recruitment, retention and development have been an important focus in Iran for decades (Bikmoradi et al., 2008; Mehralizadeh, 2005). Consequently, Iran's higher education system has changed extensively in response to economic, political, technological, social and cultural demands. Academicians, especially leaders in managerial positions, have since come to understand that the development of leadership skills and competencies through professional development training is incumbent. Likewise, the need also exists for academic leaders to identify obstacles on the path to towards effective leadership with regard to strategic planning and policy development. Furthermore, academic leadership in Iran is multidimensional and, accordingly, is understood differently from the perspectives of numerous higher educational institutions (Hamidifar, 2012).

\section{Background of the Case Study}

The past twenty years have seen the establishment of numerous private universities in Iran such as Payam-e Noor as well as nonprofit centers affiliated with various ministries such as the University of Applied Science and Technology and Islamic Azad University. These institutions exist in response to increasing social demands for higher education while reducing financial burdens on the government by the implementation of privatization. Along with this tremendous growth, the provision of well qualified professional and financial resources are important issues of contemporary debate on academic leadership and policy making (Hamidifar et al., 2013). 
Therefore, this study focuses on functional dimensions of effective academic leadership in Iran's private universities, choosing the Islamic Azad University for the case study.

The Islamic Azad University (IAU) was founded in 1982 during the early years of the Islamic Revolution. Its aim was to further the development of higher education in Iran. Its central campus in Tehran currently has more than 400 branches throughout Iran and other countries with an estimated 1.7 million students worldwide. The IAU has different types of university branches classified as follows: Category I (comprehensive), 15 branches; Category II (very large and large), 119 branches; Category III (medium), 49 branches; Category IV (small), 220 branches; and Category V (medical and dentistry), 15 branches. The main campus and branches (Categories I and II) have a substantial number of faculty members and students that comprise numerous colleges and research centers as well as various undergraduate and postgraduate programs with many resources and facilities. Categories 'III' and 'IV' have less, while category V, through collaboration with the Ministry of Health and Medical Education (MoHME) and health care organizations, plays a major role in the educational infrastructure and confers various undergraduate and postgraduate degrees including Doctor of Medicine (M.D.) and Doctor of Dental Science.

These different categories and branches of are operational nationwide in scientific research, cultural activities, and in managerial and sports programs that rely on public support. They are divided into 18 districts with transnational coordination between district branches managed by the District Secretariat. During its more than 30 years of existence, IAU has completed three developmental stages and is presently undertaking the fourth, which is a qualitative push in research, research training, knowledge acquisition and teaching, as well as research collaboration and partnerships. These stages were outlines as follows:

- First decade: Identify and utilize diverse and scattered resources and capacities (1982-1991);

- $\quad$ Second decade: Upgrade (1992-2001);

- Third decade: Qualitative Advance (2002-2011);

- Fourth decade: Enter Global Competition (2012-2021).

Islamic Azad University branches are under the supervision of the Supreme Council (Board of Trustees), which is responsible for budgeting, appointment of the IAU chancellor, development of university branches and related institutions, and making policies that adjust to situational demands. The Trustees are also responsible for faculty appointments and student exchange programs, both locally and internationally.

\section{Literature Review}

From the dawn human society, leadership has been important. In Islam's way of life, leadership is crucial for the development and maintenance of an ideal society (Ali, 2009). Based on the Holy Quran and Hadith, leadership is defined as a dynamically shared process of influence. Leaders are to be wise, knowledgeable, inspirational, accountable, resilient, merciful, kind and fair (Ali, 2009). Likewise, Shah (2006) defined leadership as social guidance with robust inferences and regard for knowledge, as well as righteous characteristics, inferring a person who communicates and behaves as a role model in the holistic sense. In Islam, the alliance of religion, knowledge and teaching generates educational leadership and connotes teaching and learning as the sacred duty of all believers. Theories of leadership are also multidimensional (Razik \& Swanson, 2010) and predominately ethnocentric (Shah, 2006). The present work is based on a number of transactional (management) and transformational leadership theories held as most important in the academic context (Bass et al., 2004; Robles, 1998; Ramsden, 1998; Wolverton et al., 2001; Kezar et al., 2006; Bryman, 2007; Bryman et al., 2009).

In the organizational context, management and leadership hold numerous meanings, definitions and interpretations (Kotter, 1990; Bush, 2007). Management is goal/result oriented, controlling and problem solving. However, leadership is oriented toward developing human relations and the organization. Nevertheless, management and leadership are, generally speaking, synonymously used in diverse contexts despite having different influential roles bearing organizational impacts such as executive planning and individual performance outcome designs. Nevertheless, they are similar in that both roles involve people at work and the achievement of organizational goals.

It is usually assumed that a person in management is a leader, but not all managers possess or implement leadership skills. Since both roles are essential for organizational success, they can be perceived as complementary systems of action (Middlehurst, 1999). In an organizational structure, leadership is far more concerned about doing the right thing, while management is more concerned about doing things right. Many studies even argue that leadership and management are distinct constructs (Kotter, 1990; Bennis et al., 1985; Rost, 1991). Zaleznik (1977) posited that leaders and managers were quite distinct and even called for different 
character types. He proposed that managers reactively respond to a demand for working with people to solve problems with little emotional involvement. On the other hand, he posited that leaders were emotionally far more proactive and sought to shape ideas into long-term solutions. Accordingly, leadership and management became distinct yet overlapping concepts. Nonetheless, many studies argue that academic leadership and management roles are more closely integrated at the departmental level with different connotations and desired outcomes per disciplinary context (Middlehurst et al., 1995; Kekäle, 2006; Ramsden, 1998).

Based on Kotter's ideas, Ramsden (1998) described management and leadership functions in an academic environment. According to Kotter (1996), most contemporary organizations balance management against leadership with a clear deference towards management that leaves leadership inadequately developed. However, as the external environment of higher educational institutions rapidly changes, leadership is far more crucial an enhancement for communal adaptation, and yet remains an inadequate substitute for effective management. Kotter (1996) believed a combination of leadership proficiency and practical management skills would provide a more productive and efficient work environment in any organization. Leithwood (1994) also supported the concept of 'transformational leaders' who practiced governance by setting institutional direction while developing organizational capacity and a corporate culture. He posited that effective transformational leaders, in the educational context, were successful managers who put forth inspirational instructions.

Similar to other organizations, higher education institutions have a systematic balancing process between management and leadership. This actually affects teaching and learning processes based on a type of 'academic cult' and reflects the dynamics of an influential individual who makes a noticeable difference in organizational performance. This dynamic is regarded as the most significant factor in the effectiveness and efficiency of any organization (Bass, 1999). Changing demands on higher education further underscores the importance of educational leadership for all levels of academia (Kouzes \& Posner, 2007).

Barnett et al. (2005) explained that academic leadership was the art of imagination from conception to communication and engagement. Academic leadership and challenges in higher education have been reviewed by a number of researchers (Barnett et al., 2005; Martin et al., 2003; Heywood et al., 2001; Becher et al., 2001; Knight et al., 2001; Moore et al., 2000; Ramsden, 1998; Mintzberg, 1998). Much of this literature involves faculty members and higher management positions such as presidents, deans and department heads. Bryman (2007) identified 13 effective leadership behaviors at the departmental level and categorized them in terms of organizational and interpersonal interactions. Scott et al. (2008) referred to five areas of academic leadership functions comprising scholarly research, networking, administration, strategic planning, performance assessment and staff management.

The present work's theoretical framework is based on the most effective and outstanding leadership style theories as espoused by Bass and Avolio (2004), Kouzes and Posner (2007), Ramsden (1998) and Leithwood (1994). The author applied their criteria to determine characteristics of effective academic leadership in terms of setting directions, organizational and personnel development for three levels of administration: central office, branch office, and faculty.

\section{Research Methodology}

The purpose of this qualitative study is to examine aspects of effective academic leadership along with challenges that impede its efficacy in the Iranian venue of private higher education. The interview protocol based on a theoretical framework and objectives, and primary data was collected via semi-structured interviews with the IAU chancellor, the vice-chancellor for research and technology, and a group of experts. Secondary data was collected from textbooks, articles, research studies, official records, newsletters, online journals and dissertations.

The targeted population included IAU experts in academic leadership. The purposive sampling technique was applied to generate a sample that addressed research objectives (Tashakkori \& Teddlie, 2003). After consultation with the IAU vice-chancellor, 35 experts from 18 IAU districts with at least 5 years of work experience in managerial positions were invited to take part in this study. Before meeting, questions and written letters explaining the research objectives were sent to the candidates. Twenty-three experts agreed to join the study, aged between 34 and 74 years, with management experience ranging between 6 and 28 years. Participants included the IAU chancellor, a vice-chancellor, 2 district heads, 6 regional research directors, 9 institutional chancellors, 2 executive directors, and 2 research deputies.

A conventional approach was used to analyze the qualitative data gathered from interviews. Responses were transcribed and translated, word for word, before content analysis via coding to develop an inductive classification system that relied on a precise method of compressing key words and statements based on explicit 
rules for coding that utilized a constant comparative method to group commonly used keywords and codes. This process allocated relational recognition between categories and subcategories. A Persian version reiteratively transcribed responses, line-by-line, to obtain a general sense that allowed for a division of data into meaningful analytical units. Analysis began by developing a list of indexed keywords with coding for each meaningful statement or segments within the developed classifications. Likewise, we manually collected similar coding to identify employed themes for a re-contextualization of the now classified data via vigorous re-examination before for the final construction of each theme. This robust coding procedure was applied to avoid misinterpretations. Hence, qualitative data analysis was done manually.

These inductive categories provided key words and statements that comprised the following: 170 codes referencing effective attributions of academic leadership; 33 codes referencing impediments; and 61 codes that identified suggestions and recommendations for leadership enhancement. Related codes were then grouped and cataloged as major themes to help determine analogous units by using descriptive words or classification type. These comprised seven categories for effective academic qualities and one category for hindrances. The author therefore used a meaningful interpretation to develop two hierarchical categorized systems, one for effective academic leadership, and another for hindrances.

\section{Findings and Discussions}

All expert participants indicated that effective academic leadership is subject to several factors including (i) the establishment of a clear strategic vision and direction; (ii) institutional development via the guidance of quality research and teaching; and (iii) the enabling of human resources by recognizing performance and the provision of academic support. Sample comments in support of these claims are now presented:

"As an academic leader, I focus on practicing Islamic values and ethical perspectives in learning, teaching and quality research. I think I have a clear and effectively shared vision, and I also communicate successfully while cooperating with international universities as extremely important elements for faculty development. I believe that strengthening a value-based culture has great impact on continual improvement in academic activities."

"There should be a system of recognition that appraises people for their performance quality. This would encourage managerial commitment and increase contributing efforts. Quality assurance processes are essential to effective leadership."

"Academic leaders should focus on facilitating quality research and excellent teaching processes to best ensure the deliverance of quality student learning outcomes. Moreover, they need to inspire the kind of collaborative teamwork that establishes conditions of trust for productive inter-relationships."

In addition, various participants referenced the notion of leadership-management jobs that fluctuated between 'setting direction and strategic planning', one hand of a continuum, to contributions to 'academic decision making, implementation, assessment and evaluation' on the other. Consequently, these leaders suffered a distinct work overload syndrome as made evident by the following remarks:

"Academic leaders have got to "walk the talk" and it is not an easy job. An academic leader is hard-pressed to cover a wide variety of work related to teaching, research and leadership with high quality."

"Effective academic leaders should have the abilities to act as role models equipped with the interpersonal and relational skills to fulfill their duties. Moreover they should manage staff appointments, performance and development, teaching and the learning environment in addition to student issues while also complying with national and institutional policies."

\subsection{The Seven Key Attributes of Effective Academic Leadership}

The result of the qualitative data analysis provided seven key attributes of effective academic leadership for three different levels of administration as follows:

\subsubsection{Setting Direction}

Accomplished by practicing Islamic values with an ethical perspective; by establishing a shared vision and institutional mission with reasonable objectives; by effective communication; by providing a history of sustainable value-based performance.

\subsubsection{Developing the Institution}

Achieved via transformational leadership by applying diagnostic and measured management methods while creating sound research and teaching models; by modifications that enhance a rewarding organizational culture 
with relevant QA indicators; by strengthening relationships both externally and internally.

\subsubsection{Developing Central Personnel}

Achieved by offering an appropriate Continuous Professional Development (CPD) model, with efficient assessment and evaluation protocols and systems.

\subsubsection{Developing Branches}

Achieved by collaborative leadership and management of resources that facilitate research and teaching activities; by modifying organizational strategies and structure to encourage creativity in a culture of entrepreneurship; by closely monitoring QA; and by networking with national and international universities.

\subsubsection{Developing Branch Personnel}

Achieved by providing effective academic support with the implementation of (CPD) that offers efficient modes of recognition for academic achievements.

\subsubsection{Developing Faculty}

Achieved by fostering team leadership and the practice of fair management protocols; by taking the lead in research and instruction; by strengthening organizational culture and implementing QA protocols.

\subsubsection{Developing Individual Faculty Members}

Achieved by offering intellectual stimulation and by providing individual support.

Figure 1 illustrates the diverse aspects identified by respondents for effective academic leadership at different management levels.

\section{One participant remarked:}

"I believe effective academic leaders deal with structural, cultural and personnel issues. They should have a clear vision of where their institution is going and how to get it there."

\subsection{Setting Direction at All Three Administrative Levels}

As shown in Figure 1, setting direction is mirrored at all three administrative levels, which respondents also highly endorsed the following concepts:

- Practicing Islamic values with an ethical perspective by displaying the moral leadership that conducts Islamic values and transcendent truths by instilling mutual trust and respect along with social responsibility and commitment to law.

- Creating a shared vision and practical mission objectives by engendering a sense of commonality. Having a collective vision that contributes to national development by pioneering the production of knowledge through the provision of teaching and research facilities that are recognized at national and international levels.

- Communicating effectively with maximal efficiency in a timely manner via automation, IT networking, formal and informal letters, brochures, online information and mass emails. Such should carry both instrumental and expressive content within and across institutional levels to inform stakeholders, academic leaders, administrators, supervisors, faculty, support staff and students.

- Creating sustainable value-based performance venues by the enhancement of quality teaching, learning and research services while promoting excellence in academic life.

- Develop central administration to reflect and direct the following:

- Practice transformational leadership through teamwork, delegation of responsibility, and the participation of academic members.

- Apply analytical and strategic management approaches that craft principle academic stratagems with astute accounting procedures.

- Create research and teaching models by drafting policies and frameworks for academic leaders in faculties and departments that maintain a current pace with academic advances in teaching and research practices.

- Modifying the organizational culture by the construction and maintenance of a common language that reflects shared ideas and core values.

- Creating Quality Assurance (QA) indicators that truly evaluate and reflect the performance of graduate 
students, faculty members, and general staff.

- Strengthening relationships externally and internally through academic cooperation with national and international universities.

- Developing personnel at institutional levels to highly represent the following concepts:

- Provision of appropriate CPD models via workshops, conferences, personal research, professional interactions, networking, group projects and mentoring.

- Creating efficient assessment protocols that guide a well-established system of evaluation and recognition that effectively monitors and identifies outstanding performances.

- Developing IAU branch levels to manifest the following:

- The practice of collaborative leadership by building trust and empowerment.

- Resource management that clarifies roles with regard to performance, teaching and research expectations.

- Facilitation of research and teaching processes by encouraging innovation and quality projects that meet the university's vision and hopes.

- Modify organizational stratagems and structure in accordance with vision, missions, and practical objectives by effective communication. Remove top directors whose behaviors reflect different values.

- Encourage a creative entrepreneurial culture by communicating shared values that deliver the innovative context for entrepreneurship.

- Monitoring QA refers to an assessment system that constantly monitors the academic performance process and outcomes.

- Networking with national and international universities through establishing academic collaboration.

- Developing people at the IAU branch level to highly reflect the following concepts:

- Provide academic support by a personal and interpersonal managerial approach that enhances learning and teaching strategies for faculty members.

- Implement faculty CPD via professional development venues for faculty and support staff in a variety of educational settings.

- Establish an efficient recognition system that elucidates and lauds faculty and support staff for their qualified achievement of annual goals.

- Development at the faculty level should reflect the following concepts:

- Fostering team leadership refers to committed groups that provide quality teaching and process management skills.

- Practicing fair management refers to efficient teaching, educational management and quality research publications by competent faculty members with resourceful responses to student needs and demands.

- Becoming a research and educational leader who promotes knowledge acquisition, and the discipline and skills applicable to research.

- Strengthening the institutional culture by promoting values that enable effective teaching and learning.

- Implementing quality assurance via assessment, reports, curriculum design and development.

- Faculty Development should reflect the following concepts:

- Facilitate intellectual stimulation by providing amenities, resources and workload adjustments.

- Provide individual support by identifying and developing opportunities and professional programs for faculty members and staff.

One participant remarked:

"Effective academic leadership is to generally focus on institutional strengths and increase the number of qualified graduated students while enhancing the efficient management of quality instruction and the provision of applied research programs that fulfill society's needs."

Leaders in Iran's private universities have tried to improve productivity with well-designed academic programs and structures but there remain numerous unfulfilled expectations. Results from this study indicate that effective 
academic leaders create a shared vision and a clearly defined course for organizational and individual development. These findings concur with many other related studies (Arasteh, 2009; Bass \& Avilio, 2004; Bikmoradi et al., 2008; Bryman, 2007; Hamidi, 2009; Hamidifar, 2012; Leithwood, 1994; Kozes \& Posner, 2007; Ramsden, 1998). Likewise, Yukl (2006) identified effective leader performance parameters in the business context. These included motivation, inspiring persona, clarification of objectives and provision of support, ongoing development, recognition of talent with rewards, team building, delegation of authority, consultation, networking, and monitoring.

The current work identified several dimensions of effective academic leadership that reflect components of contemporary leadership theories. These allowed us to conclude that effective academic leaders in managerial positions are motivated professionals with knowledge and skills pertinent to their working environment (Leithwood et al., 1999). The academic milieu should provide a shared vision supported by moral values, clear goals and stratagems via effective communications that inspire individual commitments while considering stakeholder needs - all of which reflect a transformational and collaborative leadership style (Bikmoradi et al., 2008). Academic leaders in higher education should facilitate faculty members and support staff by endorsing a continuum of professional development programs and a meritocracy-based reward system.

Effective academic leadership facilitates skilled teamwork and collaboration by efficient communications that endorse quality-based individual and collective goals and values (Ramsden, 1998). Effective leadership exercises mutual trust building modalities that inspire respect and integrity as fundamental values via operative communication skills that convey organizational commitment and genuine interrelationships between administrators, faculty members, support staff and students (Konzer \& Posner, 2007; Kotter, 1990; Ramsden, 1998). Based on these findings, academic leaders should set direction and cultivate the adoption by organization and staff of collective goals that significantly influence stakeholder value as well as commitment and resilience - all of which enhance the quality management of their educational programs and institutional research efforts.

Regarding hindrances that negatively impact effective academic leadership, the majority of leaders in managerial roles cited political influence on decision making processes, centralization of authority, ineffective communication, and unqualified human resources. They also mentioned budgetary restraints due to decreasing student populations in some branches. Participants remarked as follows:

"Political and social interventions and the dominance of a hierarchical relationship present barriers to successful leaders at Islamic Azad University. With respect to curriculum, there is an overdependence on the Ministry of Higher Education. I think each university should have the latitude to design their own curriculum as applicable to spatial planning and social demands."

"I believe centralization, bureaucracy, and the lack of efficient communication are important barriers. As there is a lack of meritocracy accompanied by budgetary shortfalls in several branches, academic leaders require greater autonomy in terms of the recruitment of capable staff and financial management."

Our data analysis categorized expert views into the five headings illustrated in Figure 2.

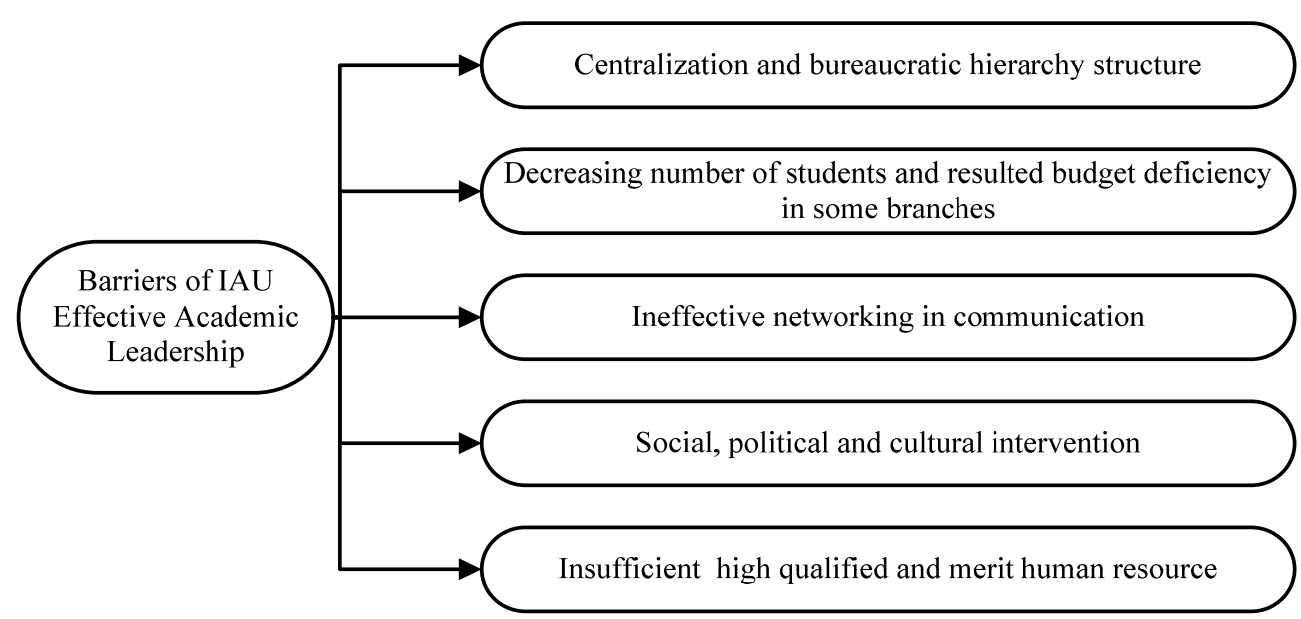

Figure 2. Barriers to effective academic leadership at IAU 
IAU Effective Academic Leadership Dimensions

\section{Setting Direction through}

- Developing institution through

-Practicing transformational leadership -Applying analytical and strategic management

-Creating research and teaching models -Modifying organizational culture

-Creating QA indicators

-Strengthening relationships externally and internally

- Developing people through

-Providing an appropriate CPD model -Creating efficient assessment and establish an evaluation system

- Developing IAU branch through -Practicing collaborative leadership -Managing the resources

-Facilitating research and teaching process

-Modifying organizational strategies and structure

-Encouraging creative and entrepreneurship culture -Monitoring QA

-Networking with national and international universities

- Developing people through -Providing academic support -Implementing CPD

-Implementing efficient recognition system

- Developing faculty through

-Fostering team leadership

-Practicing fair management

-Being research and teaching leader

-Strengthening organizational culture

-Implementing QA

- Developing people through

-Offering intellectual stimulation

- Providing individual support

Figure 1. Dimensions of effective academic leadership identified at IAU. 


\subsection{The Five Major Barriers}

- Centralization of power and a bureaucratic hierarchy refer to a top down chain of authority. The board of trustees, councils, chancellor, vice-chancellors and district heads select academic leaders for different levels of administration. Due to the hierarchical dominance, promotion may depend on personal relationship and political favorites rather than performance and merit. This heavy dependency on bureaucratic rule can reduce performance and increase inefficiency.

- Budgetary restraints in some branches due to population trends and a decreasing number of undergraduate students consequently compel some programs to close.

- Ineffective networking and communications that involve filtering, data overload, routine configurations and formality at multiple levels between branches, districts and central offices.

- Social, political and cultural interventions affecting academic leaders, as well as increased Government interventions in higher educational policy making have pronounced impacts on the autonomy of academic leaders, administrators, faculty members and students.

- Inadequate human resources, often lacking competence or sufficient qualifications and merit, lead to a high demand for qualified and adequately skilled staffing.

Expert participants recommended measures to improve effective academic leadership including decentralization; increased authority for independent fiscal decisions; staff motivation via the development of intrinsic human values; closer attention to the welfare of administrators and faculty members; merit oriented recruitment of human resources; support for more effective professional development programs at all administrative levels; and a more appropriate political environment that supports community and cultural values and venues.

\section{Conclusion and Recommendations}

Effective academic leadership concerns measured systematic attempts by leaders in managerial positions that enhance teaching and research quality by clearly directing institutional and staff development at different levels of administration. The rapid institutional transformation of external and internal dynamics calls for improved skills and competencies in academic leadership. Institutional efficiency depends on the effective development of our future academic leaders. Higher education institutions of all sizes confront major challenges and obstacles in the preparation of leaders capable of managing these challenges and hindrances. Hence, it is necessary to better understand the contextual circumstances of each institution so as to better enable the development of effective academic leaders.

Maximizing leadership capabilities at all levels of administration should be viewed as a significant component of such institutions and their faculties. Therefore, the establishment of an effective academic governance culture would successfully attract, support, train and retain the talent that ensures long-term competitive advantages (Allio, 2005; Ramsden, 1998). Effective academic leaders incorporate cultural values in sync with national dynamics and events with a global perspective that enhances leadership proficiencies and institutional performance levels (Hamidifar, 2013).

Building a leadership capacity program would involve various workshops and action-based learning projects undertaken to improve leadership competencies in managerial positions throughout an institution. As academic development is complicated, learning projects might focus on developmental opportunities for an academic leadership program with respect to the impediments cited and environmental challenges (Hamidifar, 2014). Strategically, three stages are considered to develop more effective academic leaders. Stage one would involve analyzing the environment, institution and department to discover gaps between more effective leadership performance and current functions, and then evaluate feasibility by setting criteria for essential skills and competencies. Stage two would recommend the program's scope and level. Stage three would offer a professional development program based on well-defined key factors that affect the cited domains of successful leadership to enhance administrative capabilities and overall institutional performance.

\section{References}

Ali, A. J. (2009). Islamic Perspectives on Leadership: A Model. International Journal of Islamic and Middle Eastern Finance and Management, 2(2), 160-180. http://dx.doi.org/10.1108/17538390910965167

Allio, R. J. (2005). Leadership development: teaching versus leaning, Management Decision, 43(7/8), 1071-1077. http://dx.doi.org/10.1108/00251740510610071

Arasteh, H. R. (2009). The Necessity of Using New Leadership Practices among University Presidents in Iran. Journal of Research and Planning in Higher Education, 14(4), 1-17. 
Barnett, R., \& Coate, K. (2005). Engaging the Curriculum in Higher Education. Maidenhead: Society for Research into Higher Education \& Open University Press.

Bass, B. M. (1999). Two Decades of Research and Development in Transformational Leadership. European Journal of Work and Organizational Psychology, 8(1), 9-32. http://dx.doi.org/10.1080/135943299398410

Bass, B. M., \& Avolio, B. J. (2004). Multifactor leadership questionnaire: Third edition manual and sampler set. Redwood City, CA: Mind Garden.

Becher, T., \& Trowler, P. R. (2001). Academic Tribes and Territories. Buckingham: Society for Research in Higher Education. Open University Press.

Bennis W., \& Nanus, B. (1985). Leaders: the Strategies for Taking Charge. New York: Harper Row

Bikmoradi, A., Brommels, M., Shoghli, A., Sohrabi, Z., \& Masiello, I. (2008). Requirements for Effective Academic Leadership in Iran: A Nominal Group Technique Exercise. BMC Medical Education, 8(24). http://dx.doi.org/10.1007/s10734-008-9152-2

Bryman, A. L. (2007). Effective leadership in higher education: a literature review. Studies in Higher Education, 32(6), 693-710. http://dx.doi.org/10.1080/03075070701685114

Bryman, A., \& Lilley, S. (2009). Leadership Researchers on Leadership in Higher education. Leadership, 5(3), 331-346. http://dx.doi.org/10.1177/1742715009337764

Bush, T. (2007). Educational leadership and management: theory, policy, and practice. South African Journal of Education, 27(3), 391-406.

Hamidi, Y. (2009). Strategic leadership for Effectiveness of Quality managers in Medical Sciences Universities: What Skills Are Necessary. Australian Journal of Basic and applied Science, 3(3), 2563-2569.

Hamidifar, F. (2012). Effective Leadership in Iranian Higher Education. SFIMAR Research Review, 7(2), 13-19.

Hamidifar, F. (2014). Challenges facing Islamic Azad University academic leaders in managerial positions. $\begin{array}{llll}\text { International Journal of Educational } & \text { Management, } & \text { 28(6), }\end{array}$ http://dx.doi.org/10.1108/IJEM-03-2013-0043

Hamidifar, F., Vinitwatanakhun, W., \& Rhanamay-Roodposhti, F. (2013). Developing a Model of Effective Academic Leadership at Islamic Azad University in Iran. International Journal of Management and Business Research, 3(2), 89-142.

Heywood, J., Sharp, J. M., \& Hides, M. T. (Eds.) (2001). Improving Teaching in Higher Education. Manchester: University of Salford.

Kekäle, J. (2006). Academic Leadership in Perspective. Nova Science Publishers Inc., NY, USA.

Kezar, A. J., Carducci, R., \& Contreras-McGavin, M. (2006). Rethinking the "L" Word in Higher Education: The Revolution of Research on Leadership. ASHE Higher Education Report, 31(6). San Fransisco: Jossey Bass.

Knight, P. T., \& Trowler, P. R. (2001). Departmental Leadership in Higher Education. Buckingham, SRHE and Open University Press.

Kotter, J. P. (1990). A Force for Change: How Leadership Differs from Management. New York, The Free Press.

Kotter, J. P. (1996). Leading Change. USA: Harvard Business School Press.

Kouzes, J. M., \& Posner, B. Z. (2007). The Leadership Challenge. San Francisco, CA: Josssy-Bass.

Leithwood, K. (1994). Leadership for School Restructuring. Educational Administration Quarterly, 30(4), 498-518. http://dx.doi.org/10.1177/0013161X94030004006

Leithwood, K., Jantzi, D., \& Steinbach, R. (1999). Changing leadership for changing times. Buckingham: Open University Press.

Martin, E., Trigwell, K., Prosser, M., \& Ramsden, P. (2003). Variation in the experience of leadership of teaching in higher education. Studies in Higher Education, 28(3), 247-259. http://dx.doi.org/10.1080/03075070309297

Mehralizadeh, Y. (2005). New Reforms in the Management of the University: Transition From Centralized to Decentralized Based Management in Iran. Higher Education Policy, 18(1), 67-82. http://dx.doi.org/10.1057/palgrave.hep.8300073

Middlehurst, R. (1999). New Realities for Leadership and Governance in Higher Education. Tertiary Education 
and Management, 5(4), 307-328. http://dx.doi.org/10.1023/A:1018723927486

Mintzberg, H. (1998). Covert Leadership: Notes on Managing Professionals. Harvard Business Review, 76(6), 140-147.

Moore, M. R., \& Diamond, M. A. (2000). Academic Leadership: Turning Vision into reality. Retrieved from http://dx.doi.org/www.academicla.net/documents/AcademicLeadership.pdf

Ramsden, P. (1998). Learning to lead in higher education. UK, Routlege.

Razik, T., \& Swanson, A. (2010). Fundamental Concepts of Educational Leadership (3rd ed.). Upper Saddle River, NJ: Prentice-Hall.

Robles, H. J. (1998). Leadership in Higher Education. ERIC, No. ED 426742, (May 2007).

Rost, J. C. (1991). Leadership for the Twenty-first century. New York: Praeger.

Scott, G., Coates, H., \& Anderson, M. (2008). Learning Leaders in Times of Change: Academic Leadership Capabilities for Australian Higher Education. University of Western Sydney and Australian Council for Educational Research, Sydney.

Shah, S. (2006). Educational Leadership: An Islamic Perspective. British Educational Research Journal, 32(3), 365-385. Retrieved from http://www.jstor.org/stable/30032674

Tashakkori, A., \& Teddlie, C. (2003). The past and future of mixed methods research: From data triangulation to mixed model designs. In A. Tashakkori, \& C. Teddlie (Eds.), Handbook of mixed methods in social \& behavioral research (pp. 671-702). Thousand Oaks, CA: Sage.

Wisniewski, M. A. (2007). Leadership in higher education: Implications for leadership development programs. Academic Leadership the online Journal, 2(1), 1-13.

Wolverton, M., Gmelch, W. H., Montez, J., \& Nies, C. T. (2001). The Changing Nature of Academic Deanship. ASHE ERIC Higher Education Report, 28(1). San Fransisco: Jossey Bass.

Yukl, G. A. (2006). Leadership in Organization (5th ed.). Upper Saddle River, NJ: Prentice Hall.

Zaleznik, A. (1977). Managers and Leaders: Are They Different? Harvard Business Review, 55(5), 67-78.

\section{Copyrights}

Copyright for this article is retained by the author(s), with first publication rights granted to the journal.

This is an open-access article distributed under the terms and conditions of the Creative Commons Attribution license (http://creativecommons.org/licenses/by/3.0/). 